\title{
Presencia de la narrativa policial en la literatura chilena
}

\section{Colaboración de Ramón Díaz Eterovic ${ }^{1}$}

Desde hace unas tres décadas a esta parte, la presencia del género policial o de la novela negra es una realidad incuestionable en la narrativa chilena, reflejada a través de las obras de los autores que la desarrollan y del interés que éstas despiertan entre académicos, investigadores y lectores. Este fenómeno responde en buena medida a la revalorización del género como una forma literaria que tratada con creatividad alcanza rangos de alta elaboración literaria, superando los lastres del género y expresándose mediante textos que examinan con profundidad el pulso de la sociedad.

La revalorización del género también responde a la respuesta que algunos autores dan a la situación de violencia, visible o subterránea, que ha existido y existe en nuestro país y para cuyo reflejo la forma de la novela policial entrega elementos como un eje narrativo centrado en la criminalidad, las atmósferas opresivas de las grande urbes y la figura del investigador -detective, policía, abogado o simple aficionado- como un justiciero capaz de defender valores éticos avasallados y hacerse cargo de preguntas que no todos están dispuestos a responder. A partir de esto, el género policial se constituye en el espejo que refleja la confusión del hombre común enfrentado a una realidad que cada día le parece más ajena, y como señalara Ricardo Piglia en alguna entrevista, se convierte en "un diagnóstico extraordinario del funcionamiento de la lógica social en la relación entre inmoralidad y dinero, entre poder político y poder criminal. Todos estos elementos que están presentes en el género se han convertido casi en el horizonte de la cultura contemporánea".

El género policial se despliega a través de relatos donde está presente la verosimilitud, el rescate de la poesía marginal de las grandes urbes, la parodia, el humor y la ironía. Algunos elementos provienen del cine, el comic, la música popular; todo lo cual permite construir una poética particular y recrear situaciones que generan una alta identificación de parte de los lectores. Otro elemento a destacar está vinculado con el cuestionamiento de los hechos que se narran y de la forma como se hace, y, desde luego, también la parodia al género. Y en esa búsqueda, entre otras cosas, se ha subvertido la estructura tradicional de la novela policiaca -limitada a la resolución de un problema-incluyendo incidencias y reflexiones tangenciales, caracterizaciones psicológicas y sociales

1 Destacado novelista chileno, organizador del Festival de Novela Policial Santiago Negro (2009). 
que, en definitiva, contribuyen a que este género se acerque a ese viaje literario total que ofrece toda novela. Al respecto, vale citar lo dicho por Leonardo Padura, en el prólogo de su antología Variaciones en Negro, cuando señala que "el elemento que más ha coadyuvado a establecer un espíritu de cuerpo entre los neopolicíacos iberoamericanos ha sido una común postura estética que de algún modo los define y caracteriza a todos: la de saberse contadores de historias, creadores de fábulas sobre la sociedad contemporánea (...) empeñados en sostener que la aventura es la sustancia de la mejor novelística de todos los tiempos -desde El Quijote hasta nuestros días".

El renovado interés por el género policial ha tenido recientemente dos manifestaciones en las que bien vale la pena detenerse. La primera fue la realización del Festival de Novela Negra "Santiago Negro" organizado por el Centro Cultural de España; y la segunda, la publicación del ensayo Tinta de sangre. Narrativa policial chilena en el siglo XX de Magda Sepúlveda y Clemens Franken, publicado por la Universidad Católica Silva Henríquez. Ambos hechos, y a su manera, son un testimonio respecto a que una de las manifestaciones más interesantes en la narrativa chilena de los últimos años está relacionada con la reinstalación del género policíaco como una forma literaria que constituye una profunda reflexión en torno a la relación entre crimen, política y violencia; y a la violencia como eje del funcionamiento social y de las relaciones privadas.

\section{Santiago Negro: La novela policial chilena mostró su rostro}

Desde el 14 al 18 de octubre de 2009 se realizó el primer Festival de Novela Negra Santiago Negro, actividad que reunió a escritores españoles y chilenos, profesores de literatura, periodistas, cineastas, policías, dibujantes de comic y otros artistas, en torno a un programa de más de ochenta actividades realizadas en seis escenarios de Santiago. El desafío del festival era mostrar distintas expresiones creativas vinculadas a la novela negra o novela policial, y dar cuenta de una narrativa que, sin tener una larga tradición en nuestra literatura, hoy en día tiene una destacada presencia en ella, gracias a escritores y escritoras que utilizan sus códigos para crear historias y enigmas que reflejan el funcionamiento de la sociedad chilena actual y los traumas de su historia más reciente.

El festival contó con la presencia de los reconocidos autores españoles Andreu Martín, Juan Madrid y Lorenzo Silva, y de otros más jóvenes, como Domingo Villar, Kama Gutier, Mercedes Castro y Juan Bolea. La representación chilena estuvo encabezada por escritores de la trayectoria de Poli Délano, Sergio Gómez, Bartolomé Leal, José Román, José Gai, José Miguel Vallejo, Antonio Rojas y Roberto Ampuero. A ellos se sumaron autores de reciente proyección: Juan Ignacio Colil, Martín Pérez, Gabriela Aguilera, Eduardo Contreras, Orietta de la Barra, Eduardo Soto, Francisco Miranda y César Farah, entre otros. Además de los escritores, se contó con las exposiciones de algunos profesores de 
literatura e investigadores, como Patricia Espinosa, Alvaro Bisama, Clemens Franken, Myra Silva Labarca, Adolfo Bisama y la profesora de la Universidad de Córdoba, Mirian Pino.

Uno de los principales logros del festival fue despertar la atención del público sobre un género literario en ebullición y dar a conocer a un conjunto de autores chilenos y españoles que no siempre han tenido la difusión que merece la calidad de sus obras. También se logró promover el hábito lector, a través del diálogo con los autores, la organización de la primera feria del libro policial que congregó a un interesante conjunto de editoriales y libreros, y la edición de seis números de la revista "A tiro limpio", con un tiraje que superó los cien mil ejemplares repartidos gratuitamente en bibliotecas y centros culturales. Gracias a la iniciativa del Centro Cultural de España, nuestro país cuenta desde ahora con un evento en torno a la narrativa policial que mediante su continuidad puede llegar a convertirse en un referente en el ámbito latinoamericano y compararse con absoluta propiedad con eventos similares que se realizan en España, Francia y otros países europeos.

\section{Tinta de sangre para la historia de la narrativa policial en Chile}

Respecto al libro Tinta de sangre. Narrativa policial chilena en el siglo XX de Magda Sepúlveda y Clemens Franken, lo primero que se puede apuntar es que se trata de un ensayo que aporta una serie de pistas importantes para dilucidar el misterio de la presencia que actualmente tiene la narrativa policial o criminal en nuestra literatura, expresada en la obra de autores que postulan el desarrollo de una literatura de género, y de otros que asumen sus códigos como una estrategia narrativa que en la mayoría de los casos suele ser efectiva. Tinta de sangre es un libro que abre caminos para la investigación y análisis de un género que hasta hace unas pocas décadas atrás carecía de la atención académica que se merecía. Al respecto, y como los mismos autores lo señalan, abordar el género policial como materia de la crítica literaria implica "un cuestionamiento a las viejas jerarquías, ya que la mirada canónica lo situaba distante de la calidad estética". Esto, a nuestro juicio, y sobre todo en las últimas décadas ha quedado superado por un conjunto de autores que asumen la narrativa policial no como un mero ejercicio de ingenio, sino que como un género que tratado con rigor no desmerece al lado de cualquier otra narrativa, con o sin apellidos.

En Chile, y como lo analizan los autores de Tinta de Sangre, la narrativa policial tiene su origen más evidente en la novela La muerte misteriosa de José Marini, de Januario Espinoza, publicada en el año 1912, y en los cuentos de Alberto Edwards que con el seudónimo de Miguel de Fuenzalida dio vida al detective Roman Calvo, el Sherlock Holmes chileno. De Román Calvo a nuestros días han pasado muchos crímenes de ficción bajo el puente, y lo que nos proponen Franken y Magda Sepúlveda es realizar una suerte de viaje, de 
recorrido detallado por la narrativa policial chilena, desde sus albores y hasta sus manifestaciones al finalizar el siglo XX. Un recorrido que como indican los autores es "por las principales novelas policiales" escritas en el periodo indicado, ordenadas "según el tipo de detective que guía la ficción". A partir de esta premisa, por las páginas de Tinta de sangre transcurren las peripecias de los primeros detectives chilenos, ordenadas a partir de siete relaciones establecidas por los autores: El detective contra los inmigrantes, el detective aristocrático, el detective a favor de la modernización, el detective cómplice de las mujeres, el detective contra las grandes instituciones, el detective en la globalización, y el detective frente a la imposibilidad de la verdad. Este ordenamiento permite a Franken y Sepúlveda analizar detalladamente la mayor parte de las novelas policiales escritas en Chile.

El libro de Franken y Sepúlveda es un eslabón importante en el interés académico que despierta la narrativa policial. Continúa el trabajo que ambos han desarrollado en forma individual en los últimos años y dialoga con los trabajos de otros académicos chilenos, como Guillermo García Corales, José Promis, Patricia Espinosa, Juan Armando Epple, Patricia Varas, Mabel Vargas, Fernando Moreno y Freddy Vilches, por dar algunos nombres y de paso reflejar con ellos el interés de la academia por la literatura policial. Esta sola lista, que podría ampliarse considerablemente, da cuenta de la presencia de esta literatura en las universidades como una materia de estudio que cada día adquiere mayor relevancia.

Por sus alcances, por la cantidad y calidad de la información que aporta, Tinta de sangre está llamado a constituirse en una referencia obligada para la difusión de la narrativa policial y su estudio. Sin duda que otros profesores y estudiantes de literatura encontrarán en sus páginas numerosas pistas para el desarrollo de nuevas investigaciones; y también será una guía imprescindible para el lector que quiera hacer una lectura sistemática y exhaustiva del género policial en Chile. Y, por último, es un ensayo que, al abordar una vertiente significativa en la actual narrativa chilena, permite entender las sensibilidades subterráneas que atraviesan la historia de nuestro país. Tinta de sangre plantea interrogantes, arroja luces sobre algunos misterios y despierta una apremiante curiosidad sobre la obra de la mayoría de los autores que han escrito la historia de la narrativa policial en nuestro país.

Festivales, ensayos y recopilaciones de cuentos como la reciente publicación de editorial LOM, Letras Rojas. Cuentos negros y policíacos chilenos, permiten reconocer la vitalidad del género policial en nuestra literatura y constituyen un puente cargado de enigmas que buscan conectar la ficción y la realidad con los lectores que siguen atentamente la evolución de un género que desde su orígenes ha contado con la complicidad de quienes buscan reflexión y entretención a través de las páginas de un libro. 